\title{
Dissection of jasmonate functions in tomato stamen development by transcriptome and metabolome analyses
}

\author{
Susanne Dobritzsch ${ }^{1}$, Martin Weyhe', Ramona Schubert ${ }^{1}$, Julian Dindas ${ }^{1,4}$, Gerd Hause², Joachim Kopka ${ }^{3}$
} and Bettina Hause ${ }^{1 *}$

\begin{abstract}
Background: Jasmonates are well known plant signaling components required for stress responses and development. A prominent feature of jasmonate biosynthesis or signaling mutants is the loss of fertility. In contrast to the male sterile phenotype of Arabidopsis mutants, the tomato mutant jai1-1 exhibits female sterility with additional severe effects on stamen and pollen development. Its senescence phenotype suggests a function of jasmonates in regulation of processes known to be mediated by ethylene. To test the hypothesis that ethylene involved in tomato stamen development is regulated by jasmonates, a temporal profiling of hormone content, transcriptome and metabolome of tomato stamens was performed using wild type and jai1-1.
\end{abstract}

Results: Wild type stamens showed a transient increase of jasmonates that is absent in jai1-1. Comparative transcriptome analyses revealed a diminished expression of genes involved in pollen nutrition at early developmental stages of jai1-1 stamens, but an enhanced expression of ethylene-related genes at late developmental stages. This finding coincides with an early increase of the ethylene precursor 1-aminocyclopropane-1-carboxylic acid (ACC) in jai1-1 and a premature pollen release from stamens, a phenotype similarly visible in an ethylene overproducing mutant. Application of jasmonates to flowers of transgenic plants affected in jasmonate biosynthesis diminished expression of ethylene-related genes, whereas the double mutant jai1-1 NeverRipe (ethylene insensitive) showed a complementation of jai1-1 phenotype in terms of dehiscence and pollen release.

Conclusions: Our data suggest an essential role of jasmonates in the temporal inhibition of ethylene production to prevent premature desiccation of stamens and to ensure proper timing in flower development.

Keywords: Array hybridization, Desiccation, Ethylene, Flower development, Jasmonic acid, Jasmonic acid-insensitive, Metabolite profiling, Pollen development

\section{Background}

Jasmonic acid (JA) and its metabolites, such as its methyl ester (JAME) or amino acid conjugates, all of them commonly named jasmonates, are ubiquitously occurring signaling compounds in plants and are formed in response to biotic and abiotic stress as well as in development [1]. Jasmonates are lipid-derived compounds synthesized from $\alpha$-linolenic acid released from plastid membranes and are synthesized by one of seven different branches of the lipoxygenase (LOX)

\footnotetext{
* Correspondence: bhause@ipb-halle.de

'Leibniz Institute of Plant Biochemistry, Weinberg 3, D06120 Halle, Germany Full list of author information is available at the end of the article
}

pathway $[2,3]$. LOX and the two following enzymatic steps are located in the plastids and involve the action of an ALLENE OXIDE SYNTHASE and an ALLENE OXIDE CYCLASE (AOC) leading to formation of the intermediate cyclopentenone cis-12-oxo-phytodienoic acid (OPDA). Further reactions occur in peroxisomes and include the OPDA REDUCTASE 3 (OPR3) and three cycles of fatty acid $\beta$-oxidation. Within the JA pathway the AOC-catalyzed step is regarded as the crucial step as here the exclusive formation of the enantiomeric form occurring in natural cyclopentanones like JA is facilitated $[4,5]$. JA can be enzymatically converted into numerous conjugates and derivatives, some of which are biologically 
active, such as JAME [6], cis-jasmone [7,8] and JA-amino acid conjugates $[8,9]$. Among the latter, (+)-7-iso-jasmonoyl isoleucine (JA-Ile) was demonstrated to be the biologically active form of jasmonates by mediating binding of the coreceptor proteins CORONATINE INSENSITIVE1 (COI1) and JASMONATE ZIM DOMAIN (JAZ) [10-13].

JA-Ile is involved in most JA-dependent processes mediated by the F-box protein COI1 in a proteasomedependent manner [1]. As evidenced by phenotypic analyses of Arabidopsis mutants, jasmonates are involved in various developmental processes, one of them being flower development. The coronatine- and jasmonateinsensitive mutant coil [14] as well as the JA biosynthesis mutants fad3-2fad7-2fad8 [15], dad1 [16], opr3 [17], and dde1 [18] cannot produce viable pollen. All of these mutants exhibit an identical male-sterile phenotype: (1) anther filaments do not elongate sufficiently to position the locules above the stigma at anthesis, (2) anthers lack the proper dehiscence of the stomium at the time of flower opening, and (3) pollen is produced in a smaller amount than in the wild type and does not germinate $[19,20]$. Combining these phenotypic features with the fact that mutants defective in JA perception and/or synthesis have much less water loss in anther tissue than wild type plants, JA has been thought to control dehiscence by regulating water transport into the filament and out of the anthers of Arabidopsis $[16,21]$. Moreover, it has been assumed that JA is required for the expression of genes involved in water transport in anthers [16].

Similar to the Arabidopsis mutant coil, a mutant impaired in the tomato ortholog of COI1 was isolated in a genetic screen for plants that are unable to accumulate defense-related proteins in response to JAME application [22]. This mutant, called jasmonic acid-insensitive1-1 (jai1-1) and identified in a screen of a fast-neutronmutagenized population of Micro-Tom plants, exhibits a $6.2-\mathrm{kb}$ deletion in SlCOI1, is deficient in all JA-Ile mediated responses and fails to set seeds [23]. Reciprocal crosses revealed that jai1-1 plants are male fertile, but female sterile [22]. This is in agreement with data showing that not only JA perception but also JA formation is required for female development: AOC protein occurs specifically in ovules, and OPDA, JA, and JA-Ile accumulate preferentially in the ovary of flower buds, where the levels markedly exceed those detected in non-stressed leaves [24]. The organ-specific accumulation of JA and most importantly - of JA-Ile may result in organ-specific regulation of gene expression. Indeed, a number of JAinduced genes are specifically expressed within ovules [24], but their regulation by JA in gametophytic organs has not yet been proven.

The ability of jai1-1 pollen to induce normal seed set when crossed to a wild type pistillate flower indicates that JA perception and downstream signaling events might not be essential for the production of viable pollen in tomato [23]. However, jai1-1 plants also exhibit defects in male reproductive function, such as a reduction in pollen viability and germination, tissue collapse and browning of the anther cones, and a protrusion of the stigma from the anther cone of mature flowers [23]. Therefore, a role of JA in male gametophyte development in tomato is suggested, especially in controlling anther senescence and dehiscence.

Dehiscence is typical for maturing stamen $[25,26]$ and represents a coordinated process occurring in specialized cells of the anther that determine the site of anther opening (for review see [27]). This multistage process involves localized cellular differentiation and degeneration to facilitate complete anther opening and pollen release [26]. In tobacco, another Solanaceae species, the final events of dehiscence, such as degeneration of the stomium cells and dehydration are affected by ethylene (ET) $[27,28]$. Treatment of nearly mature anthers with ET accelerated dehiscence, whereas an ET-perception inhibitor retarded dehiscence, and ET-insensitive plants exhibited a loss of anther dehiscence synchrony with flower opening [28]. In tomato, overexpression of SIERF.B3 encoding a dominant repressor variant of the tomato ET-response factor (ERF), led to a constitutive ET response and sensitivity, which was accompanied by the protrusion of stigma from the stamen cone [29]. These data suggest a scenario where ET acts in stamen development of Solanaceae species by regulating stamen dehiscence and pollen release. Whether ET biosynthesis and function might be changed due to JA insensitivity in jail-1 is an open question and is addressed by this work.

To get insights into the putative role of jasmonates and the mechanisms involved in stamen development, we performed comparative analyses of stamen development in tomato wild type and jai1-1 mutant plants in terms of profiling of jasmonates as well as transcript and metabolite profiling. We show that JA levels increased transiently peaking at a middle-bud stage in wild type stamens, whereas they were constantly low in jai1-1 stamens. Jai1-1 stamens are characterized by an enhanced expression of ET-regulated genes, higher levels of desiccation-related metabolites and a premature rise of the ET precursor 1-aminocyclopropane-1-carboxylic acid (ACC) starting at the developmental stage of highest JA level in wild type. To further prove these results, application of JA to transgenic plants, which are unable to synthesize JA, and a cross of jai1-1 with an ETinsensitive mutant (Never Ripe, NR) were performed. The data suggest a role of JA as inhibitor of a premature function of ET, which itself regulates anther dehiscence and pollen release. 


\section{Results}

Wild type stamens at stage 3 contain highest level of JA and JA-lle

Senescence of anther cones is a prominent phenotypic feature of jai1-1 flowers [23]. To get insights into the processes leading to this stamen phenotype, flower development of jai1-1 plants and the corresponding wild type was analyzed. Timing of flower development in wild type (cv. MicroTom) and jai1-1 mutant plants was highly similar. After five weeks of cultivation, the first open flower appeared at the oldest inflorescence and younger flower buds of different stages were visible simultaneously (Figure 1a). The flower bud stages were classified in developmental stages using parameters such as bud size, opening of the sepals and color of the petals. The youngest stage (stage 1 in Figure 1a) represented a small bud completely enclosed by sepals, whereas the oldest stage (stage 6 in Figure 1a) represented the open flower showing bright yellow petals. The stamen cone of jai1-1 mutant open flowers frequently showed a dehiscent and senescent tip (Figure 1b, stage 6), whereas stamens of other developmental stages did not show obvious phenotypic differences to wild type stamens.

To elucidate the occurrence of jasmonates in male reproductive organs, stamens were collected from each developmental stage of wild type and jai1-1 plants and the levels of OPDA, JA and JA-Ile were determined (Figure 1c). The OPDA content was similar in all stages and did not differ significantly between wild type and jai1-1. This contrasts to the levels of JA and JA-Ile, which both exhibited a significant maximum in wild type stamens at stage 3 and dropped down to levels below the detection limit in stamens of open flowers (Figure 1c). Most importantly, the levels of JA and

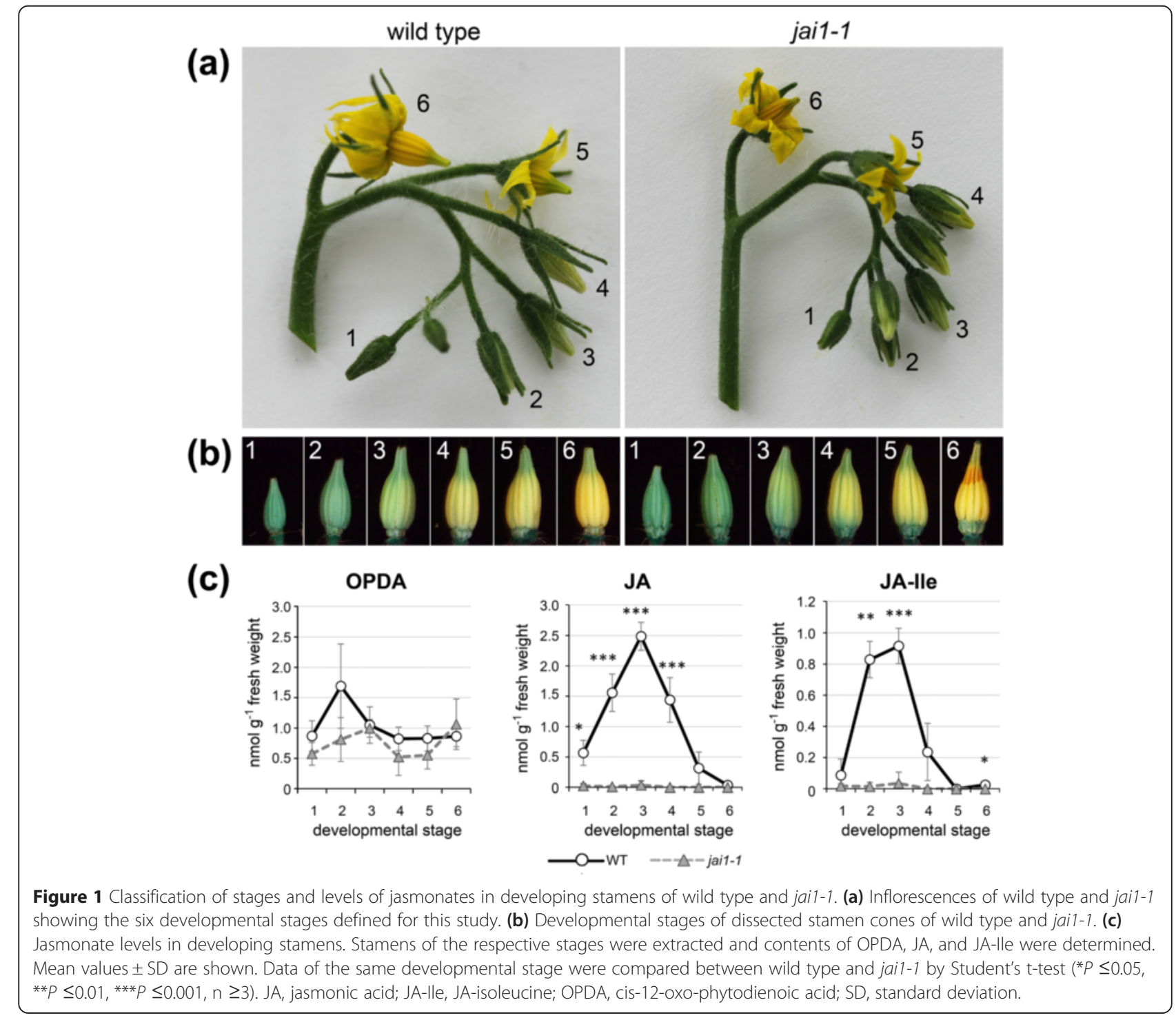


JA-Ile were almost below the detection limit in jai1-1 stamens of all developmental stages. Thus, in addition to the JA insensitivity, stamens of jail-1 plants are characterized by an absence of active jasmonates possibly caused by the missing positive feed-back in JA biosynthesis and JA-induced gene expression known for developmental processes [1]. As a result, the JA insensitivity might lead to severe alterations in transcript and metabolite accumulations in stamens of jai1-1 in comparison to wild type.

\section{Jasmonate-insensitivity alters the transcriptome in stamens}

To elucidate the role of jasmonates in stamen development, transcript profiling was conducted for stamens of developmental stages characterized by maximum differences in JA/JA-Ile contents. RNA isolated from dissected stamens of stages 1, 3 and 6 of both genotypes was used for hybridization of Agilent Tomato Arrays. To find JA-regulated genes, the Agilent data were quantilenormalized and analyzed using the ArrayStar software as described in the Methods section. The comparison between stamens of wild type and jai1-1 in each developmental stage revealed 450 genes to be differentially expressed in stamens of both genotypes (Figure 2 and Table S1 in Additional file 1). Most of the identified genes showed stage-specific differential expression. Only a minor part of genes appeared to be differentially expressed in two or three developmental stages. Moreover, a strong correlation between the number of differentially regulated genes and the JA/JA-Ile levels was found. The highest number of regulated genes was detected in stage 3 showing the highest JA/JA-Ile levels in wild type (Figure 2c). It turned out that most of the differentially expressed genes occurring in sections 1 , $1+3$, and $1+3+6$ of the Venn diagram exhibited lower expression levels in jai1-1 (blue labelled numbers in Figure $2 \mathrm{~b}$ ) pointing to a positive regulatory role of jasmonates in early stamen development. This contrasts to the genes occurring exclusively in stage 3 and 6 , in which most of them exhibited higher expression levels in jai1-1 than in wild type (WT) stamens (red labelled numbers in Figure 2b). Here, a predominantly negative regulatory role of jasmonates in the later stages of stamen development is suggested.

The differentially expressed genes were assigned to 14 groups according to their transcript levels in WT and jai1-1 and to their kinetics over the three stages analyzed (Figure 2c and Figure S1 in Additional file 2). The majority of genes were classified into groups II, V and VIII showing decreasing transcript levels during stamen development, and into groups VI and IX showing transient increase or decrease at stage 3. Note that especially for groups II and V, the JA responsiveness was stronger in the stage before reaching the maximum of jasmonate levels. Genes in groups VI and IX have opposite profiles of transcript accumulations between WT and jai1-1 peaking at stage 3, which shows the maximum JA/JA-Ile levels in WT stamens (Figure 1c). Among the positively JAregulated genes were well-described JA-responsive genes, such as JAZ1 (SGN-U579837), JAZ3 (SGN-U564449) and JAZ8 (SGN-U576446) [12]. Transcript accumulation of these genes was validated by quantitative RT-PCR using RNA from all defined developmental stages of stamen of an independent experiment (Figure S2 in Additional file 2). Transcript levels of all three genes exhibited a transient maximum at stage 3 correlating with the maximum JA/JA-Ile levels. The gene encoding the JA biosynthetic enzyme AOC, however, did not show a differential regulation between WT and jai1-1 (Figure S2 in Additional file 2) pointing to a preferentially developmental regulation of its expression. This is reflected by the level of OPDA, which was not significantly different between WT and jai1-1 (Figure 1c).

All identified differentially expressed genes could be assigned to 20 functional classes (Figure 2b). The highest numbers of differentially expressed genes occurred in the classes 'transcription factors and regulators' (51), 'signaling' (29), 'defense' (40) and 'secondary metabolism' (58). This coincides with a putative role of jasmonates due to the well-described functions of jasmonate-induced genes [1]. Additionally, genes encoding lipid transfer proteins, peptide transporters and UDP glucosyltransferases were among the positively JA-regulated genes showing a diminished expression in early stamens (stage 1) of jai1-1 in comparison to WT (Table S1 in Additional file 1). Their putative gene products might be involved in pollen nutrition.

Therefore, pollen morphology and development was analyzed using cross sections of chemically fixed and embedded stamens (Figure 3). In the WT stamen at stage 1, late unicellular microspores were detected showing small vacuoles (Figure 3a, 1). Pollen at bud stage 2 was in the bicellular stage and exhibited a large central vacuole (Figure 3a, 2). Simultaneously, the tapetum started to degrade. At stage 3, all pollen grains showed a high number of starch grains, and the vacuoles had disappeared (Figure 3a, 3). During the following stages, starch appeared to be degraded and the cytoplasm reached a glassy state (Figure 3a, 4). In jai1-1 stamens, however, different developmental pollen stages were detectable simultaneously and the development of microspores and pollen occurred faster than in WT stamens. The morphological features described for the WT appeared at least one stage earlier. Central vacuoles and starch grains appeared in pollen of stage 1 and 2, respectively, and the cytoplasm was in the glassy state already at stage 3 (Figure 3b, 1-3). Most importantly, the tapetum was not detectable in stage 1 accompanied by a 


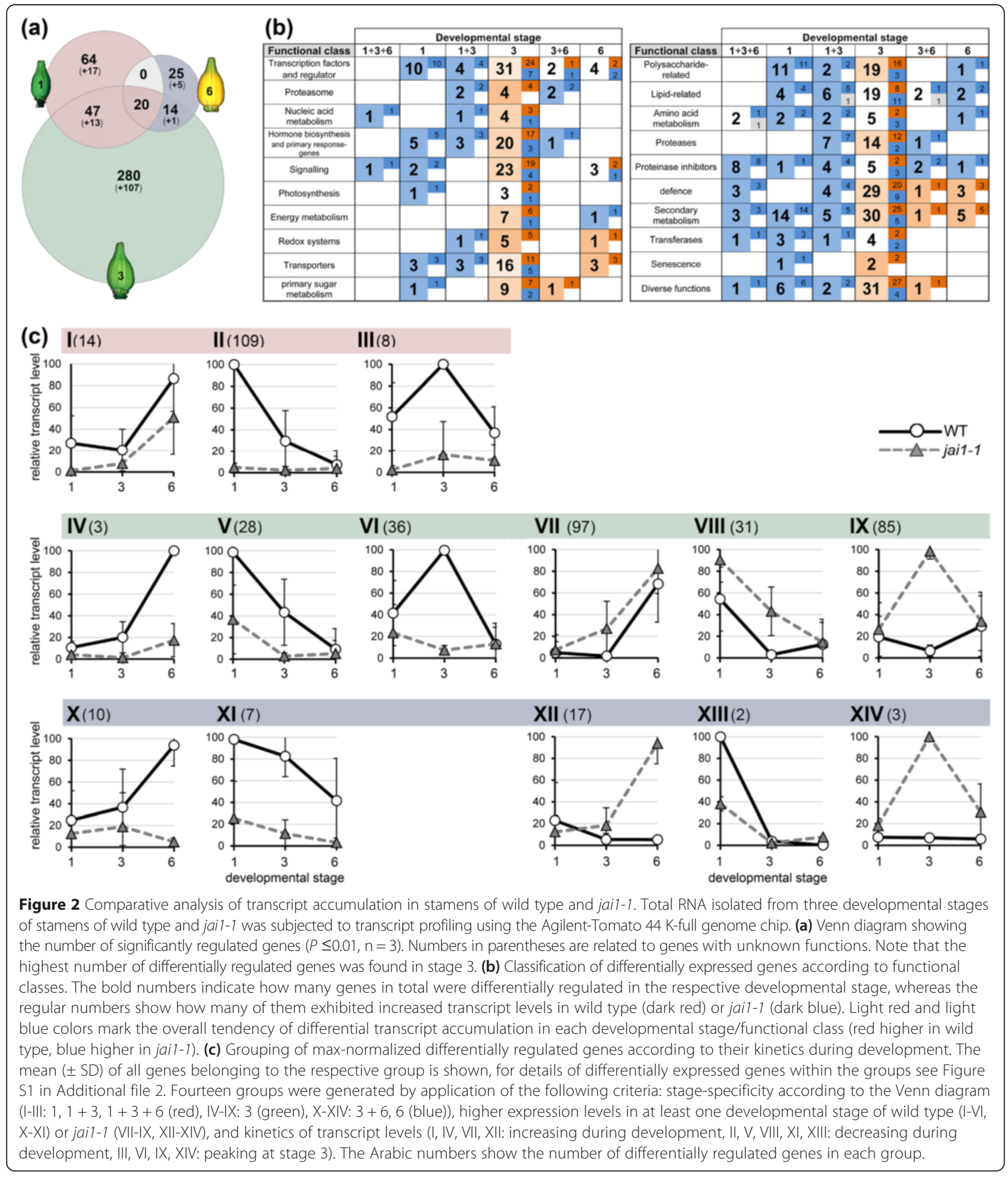

high number of aborted pollen at the final stage of the development (Figure 3b, 4). The abnormal morphology of pollen of jai1-1 supports the assumption drawn from transcript data that jasmonates are important for the timing of pollen development and might affect the nutrient supply of developing pollen.
Searching the differentially expressed genes for candidates that might have regulatory functions in late stamen development, genes related to ET-dependent processes stood out (Table S1 in Additional file 1). Among these, genes encoding the following classes of proteins were identified: ET-related TFs acting as 'master regulators' 


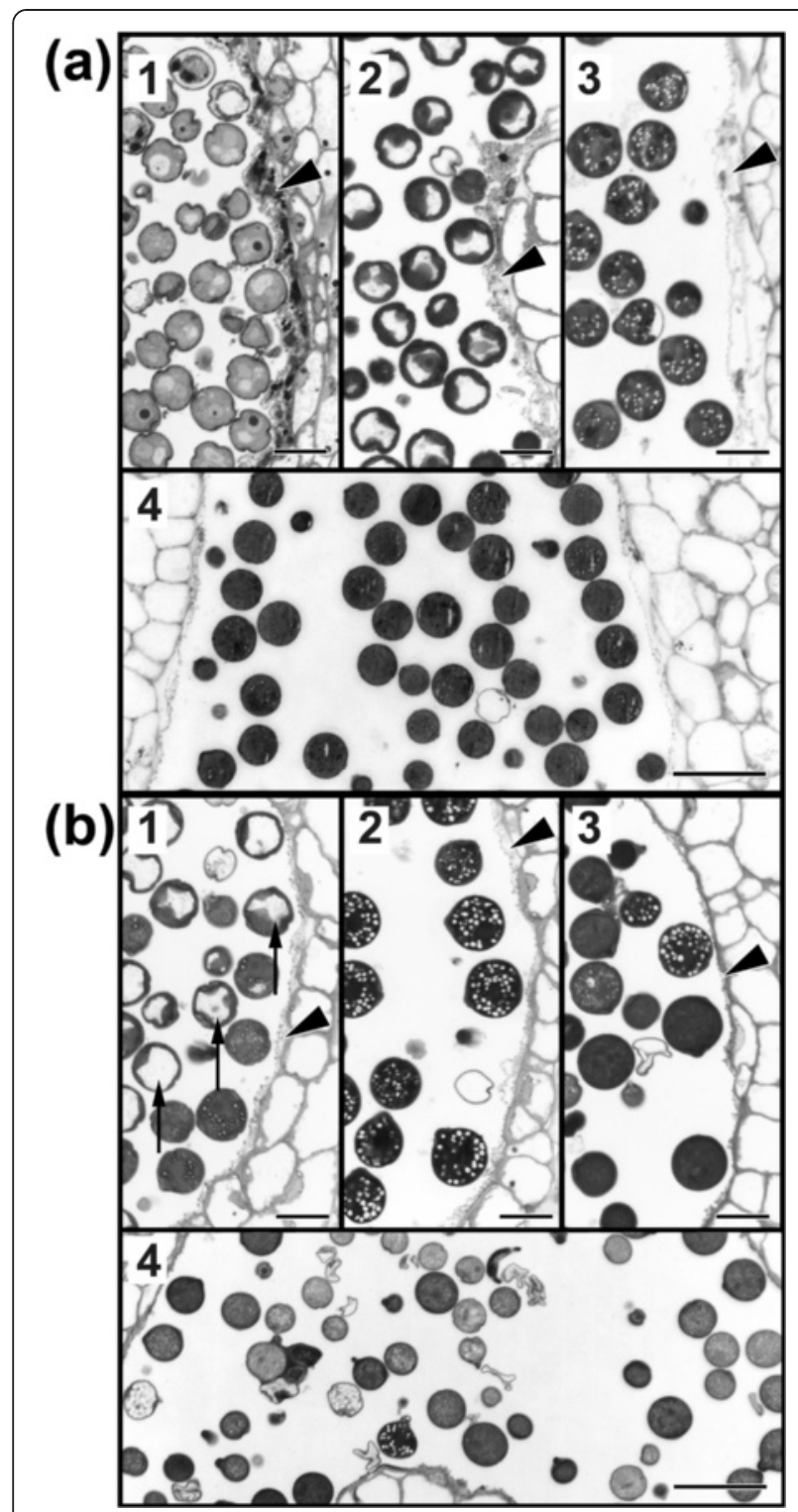

Figure 3 Pollen development in wild type and jai1-1. Semi-thin cross-sections of anthers of wild type (a) and jail-1 (b) stained with toluidine blue. The developmental stages are indicated by numbers. Note the high number of aborted pollen grains in jail-1 (b 4). Pollen of jail-1 appear premature in development as shown by typical features, such as occurrence of the big central vacuole (arrows in b1), presence of starch grains (b1 - b3) and the glassy state (b3) appearing first in wild type from stage 4 onwards. Additionally, premature degeneration of tapetum (arrow heads) is visible in anthers of jai1-1. Bars represent $20 \mu \mathrm{m}$ in (a1-3) and (b1-3), and $50 \mu \mathrm{m}$ in (a4) and (b4).

such as RIN-MADS TF (SNG-U578471) and MADSFruitfull TF1 (SGN-U578128), enzymes involved in ET biosynthesis such as 1-aminocyclopropane-1-carboxylic acid (ACC) synthase 8 (ACS8, SGN-U565888) and ACC oxidase-like (SGN-U577773), proteins involved in ET signaling such as AP2/ERF domain containing TF (SGN-U577093) and ET receptor 6 (SGN-U581694) as well as ET-induced proteins such as mitochondrial alternative oxidase AOX1B (SGN-U5589545), pirin-like protein (SGN-U574326), dehydrin DHN1 (SGN-U590489) and endoglucanase 1 (SGN-U570620).

For a validation of these selected candidates, we used a new set of plants and all defined developmental stages of stamen to determine their relative transcript levels by quantitative RT-PCR (Figure 4). Transcript levels of all selected genes were at the detection limit at early developmental stages of WT stamens and started to rise earliest in stage 5 (SGN-U578128) or stage 6 (SGN-U592775). In stamens of jai1-1, however, these transcripts were detected at earlier stages and to higher levels. These data suggest that the absence of JA/JA-Ile and/or jasmonate signaling in jai1-1 stamen might lead to an early or premature ET biosynthesis and action and subsequently might contribute to the early senescence and dehiscence observed in stamen of jai1-1.

\section{Jasmonate-insensitivity alters the steady state levels of} soluble metabolites in stamens

Metabolite profiling was performed using stamens of stage 1, 3 and 6, which were collected and subjected to non-targeted metabolite profiling. By analyzing polar compounds using gas chromatography-mass spectroscopy (GC-MS), we could detect about 100 compounds showing significantly different levels in stamens of WT and jai1-1 in at least one developmental stage (Table S2 in Additional file 1). From these, around two thirds could be assigned to known substance classes (Figure 5). Most of the differential compounds were detectable in stage 3 (Figure 5a), which had the highest JA levels in wild type stamens. Comparing the levels of the identified compounds, it became obvious that in stage 1 most of them exhibited a lower content in jai1-1 than in WT, whereas differentially occurring compounds in stamens of stages 3 and 6 showed higher levels in jai1-1 (Figure 5b).

Six different groups of metabolites were defined according to the different levels in WT and jai1-1 stamens and to their kinetics during development from stage 1 to stage 6 (Figure 5c and Figure S3 in Additional file 2). Only a few metabolites exhibited a decrease during development or a transient increase peaking at stage 3, whereas nearly $80 \%$ of the identified metabolites belonged to groups I and IV showing an accumulation during development. Among them, about $60 \%$ of metabolites showed higher levels in jai1-1 than in WT stamens (group IV in Figure $5 \mathrm{c}$ ). In group IV, mainly sugars, sugar acids and amino acids were found. As exemplified for selected monosaccharides (glucose, fructose), di- and trisaccharides (sucrose, raffinose, trehalose, 1-kestose), sugar alcohols (myo-inositol, galactinol), and amino acids (proline, glycine, valine, methionine), these metabolites showed low levels in WT stamens at stage 1 , followed by a slight 


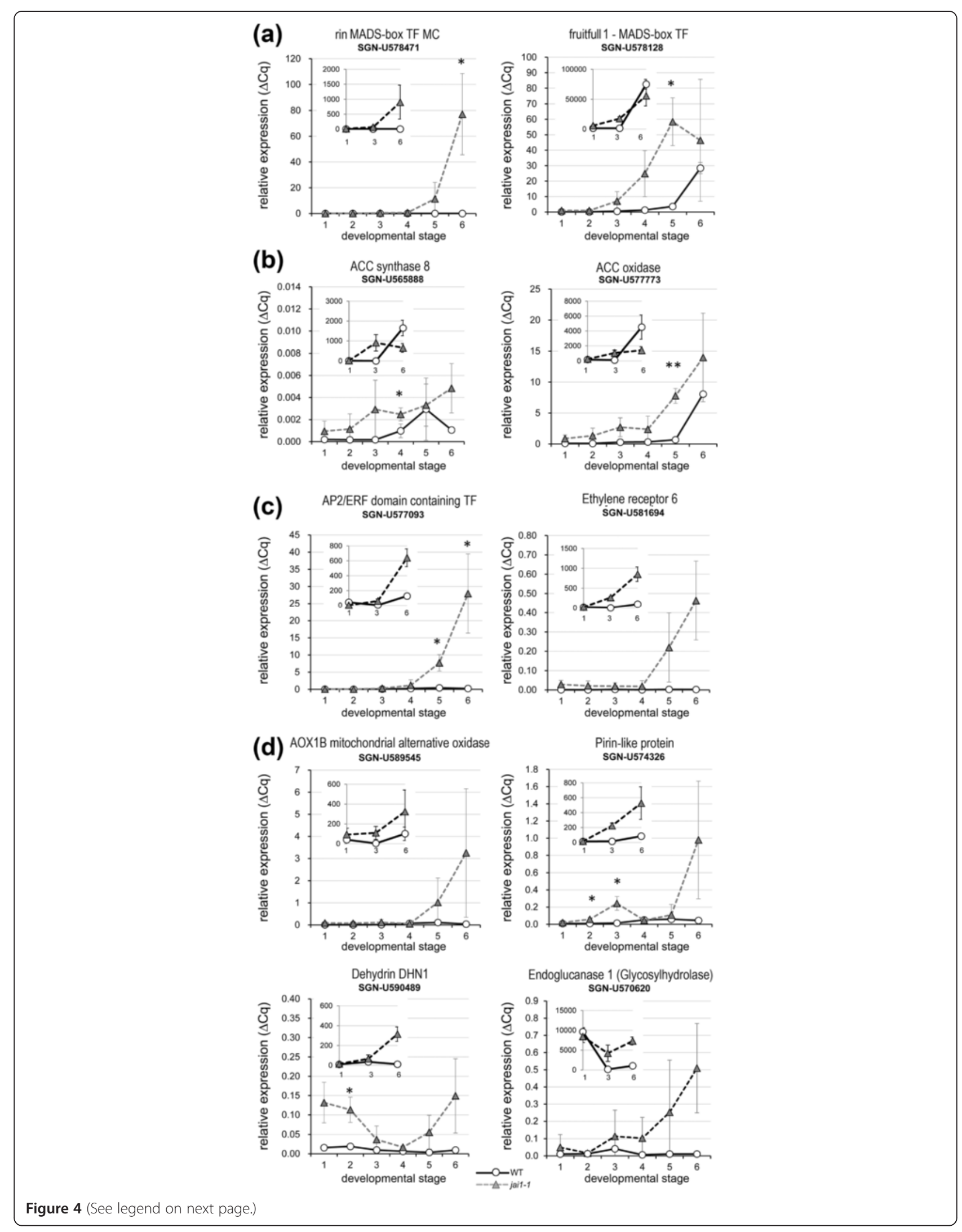


(See figure on previous page.)

Figure 4 Transcript accumulation pattern of ethylene-related genes in developing stamens of wild type and jai7-1. Relative transcript levels of genes encoding ET-related TFs acting as 'master regulators' (a), ET biosynthetic enzymes (b), proteins involved in ET-signaling (c), and of ET-response genes (d). All transcript levels were determined by RT-qPCR and set in relation to SITIP41. The inset in each diagram visualizes the signal intensity obtained from microarray analysis. Mean values \pm SD are shown. Data of the same developmental stage were compared between wild type and jai1-1 by Student's t-test ( ${ }^{*} P \leq 0.05,{ }^{* *} P \leq 0.01, \mathrm{n}=3$ ). ET, ethylene; SD, standard deviation.

change at stage 3 and a moderate increase at stage 6 (Figure S4 in Additional file 2). In jai1-1 stamens, however, some of them already showed higher levels at stage 1 , many of them showed high levels at stage 3 , and all of them increased drastically at stage 6 resulting in contents up to six-fold higher than those in WT stamens at this stage (Figure S4 in Additional file 2). Photometric measurements of glucose, fructose and sucrose performed for all six defined developmental stages confirmed the data obtained by metabolite profiling and revealed a continuous accumulation of these sugars in stamens of jai1-1 resulting in significantly higher levels than in WT stamen (in Figure S5 in Additional file 2). This contrasts to sugar phosphates, which accumulated over development in WT stamens, but exhibited lower levels in jai1-1 stamens (Table S2 in Additional file 1).

Taken together, the enhanced content of sugars as well as amino acids known as protective compounds in response to osmotic stress [30] points to increasing water loss attributing to the premature dehiscence in jai1-1 stamens. Interestingly, the higher levels of osmotically active compounds coincided with a higher osmolality of the cellular fluid in jai1-1 stamens (Figure 6a). In all developmental stages, jai1-1 stamens exhibited a significantly increased osmolality, reaching at stage 6 about twice the levels measured in WT stamens. This was accompanied by a diminished accumulation of starch in stamens of jai1-1 in comparison to WT stamens as visualized by staining of fresh sections (Figure $6 \mathrm{~b}$ ).

\section{Jasmonate-insensitivity alters ethylene production and function in stamens}

The transcriptome and metabolite data indicate an early rise in ET levels in stamen of jai1-1. Therefore, the content of its precursor ACC was determined in stamens of WT and jai1-1 (Figure 7). Indeed, the rise in ACC occurred in jai1-1 at least one stage earlier than in WT stamens and is highly correlated to the expression profiles of ET biosynthesis and ET response genes (see Figure 4). Altogether, this points to a premature ET biosynthesis and signaling in jai1-1 stamens that in WT stamen might be down-regulated by jasmonates.

To verify this hypothesis, we applied JA to developing flower buds of tomato. Since WT stamen already contain high levels of JA/JA-Ile (Figure 1c), which might be sufficient for down-regulation of ET-related genes, transgenic
Micro-Tom plants expressing an SIAOC-RNAi construct under control of the $35 \mathrm{~S}$ promoter were used [31]. These plants are characterized by diminished JA levels and exhibit a jai1-1-like phenotype. Repeatedly performed application of JA to WT flower buds starting at stage 2 resulted in enhanced transcript levels of JA-regulated genes in stamen of stage 5 (Figure 8a). In stamen of SlAOC-RNAi, however, a significant downregulation of selected ET-related genes, such as those encoding ACS8, ACO, ERF-6 and AOX1B, was detected (Figure $8 \mathrm{~b}$ ). This down-regulation of ET related transcripts points to a negative regulatory role of JA in late stamen development.

To prove the hypothesis that JA insensitivity accompanied by premature ET action leads to early dehiscence, water content in developing stamens was determined (Figure 6c). Wild type stamens showed increasing water content up to stage 3 followed by a slight, but constant loss of water until anther maturation (stage 6). In contrast, jai1-1 stamens did not show increasing water content in stage 3 and exhibited a much stronger water loss during further development resulting in a maximum difference to WT at stage 6. Cross sections of fresh stamen cones revealed that stamens of WT flower buds of stages 2 and 3 exhibited a high amount of locular fluid filling the space between developing pollen grains (Figure 6d). This fluid was nearly absent in jai1-1 anthers of the same developmental stage correlating with the differences in water content. Consistently, the premature dehiscence is reflected also by premature pollen release from jai1-1 stamens tested by shaking anthers followed by counting the released pollen (Figure 9). Only a few pollen were released from WT stamens at stage 5 and the majority of pollen was released in stage 6, whereas pollen release in jai1-1 started already in stage 4. This is also reflected by the closed stomia of WT stamen at stage 4, whereas they are already opened in jai1-1 stamen at the same stage (Figure S6a, b in Additional file 2). In summary, the lower water content, the absence of fluid in the locule of developing stamens, and the premature release of pollen in jai1-1 point to a deregulated function of ET in control of water content and dehiscence of tomato stamens not only in the mature stage, but already during development of the flower bud.

To test this, pollen release in mutants affected in ET perception, such as Never Ripe (NR, [32]) or showing a 


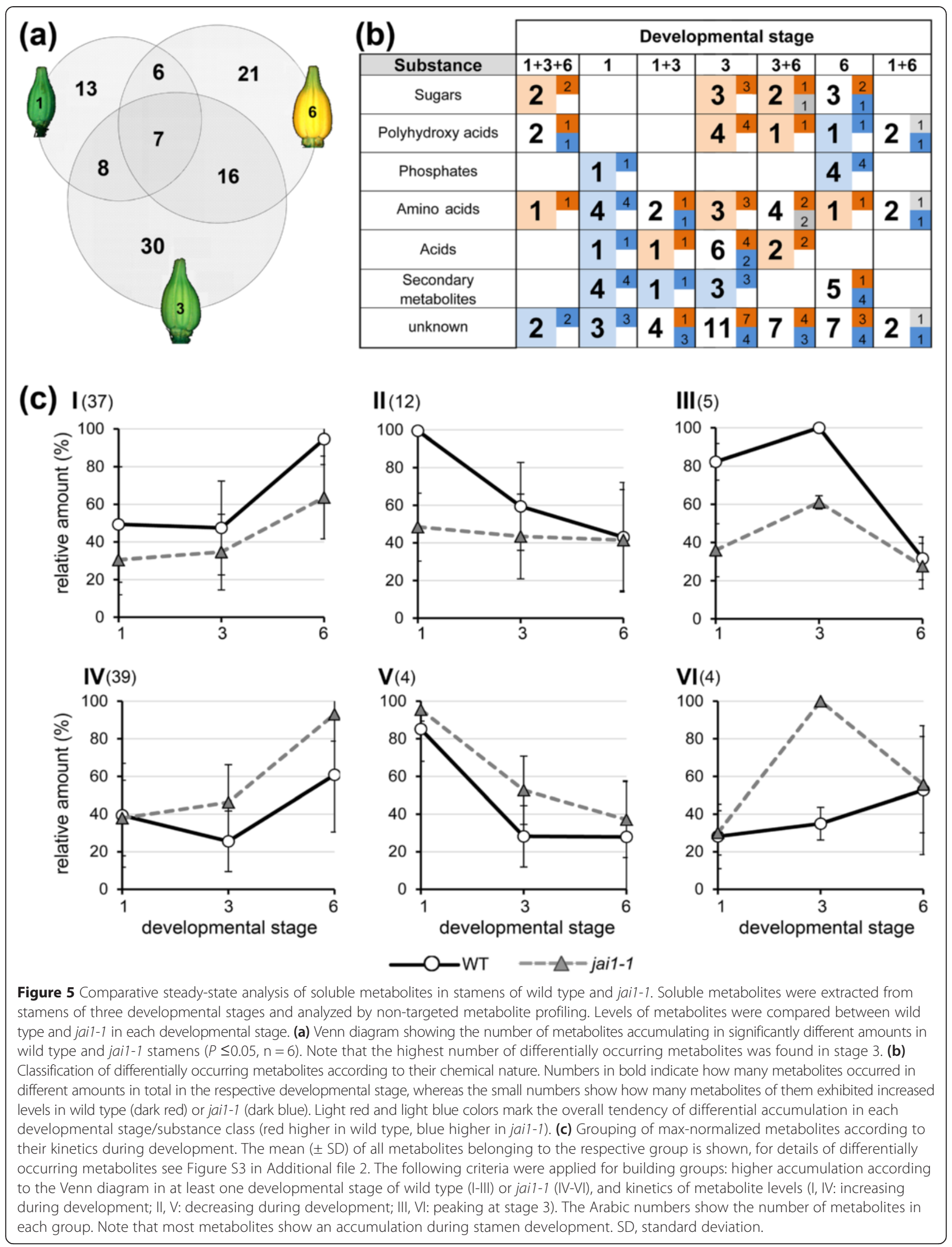



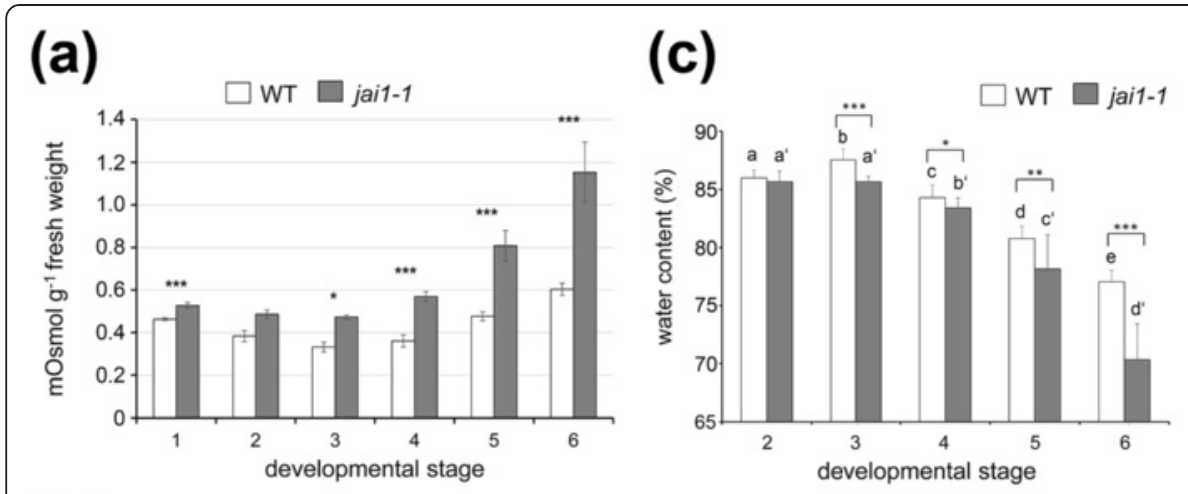

\section{(b)}

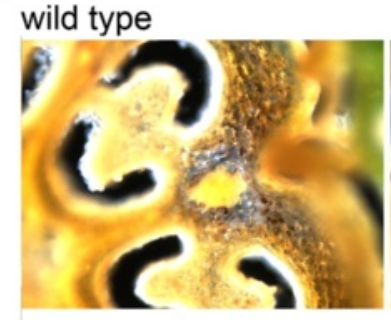

jai1-1 stage 1

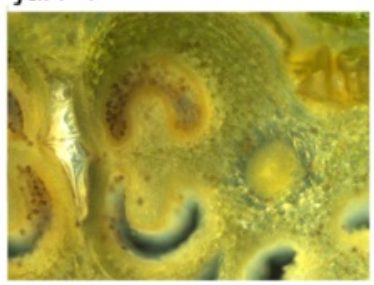

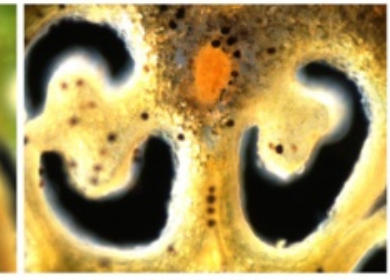

stage 3

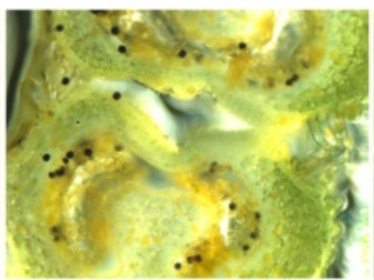

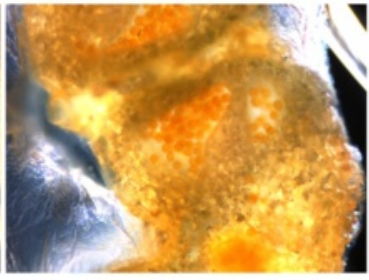

stage 6

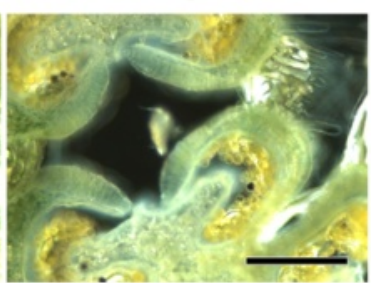

(d)

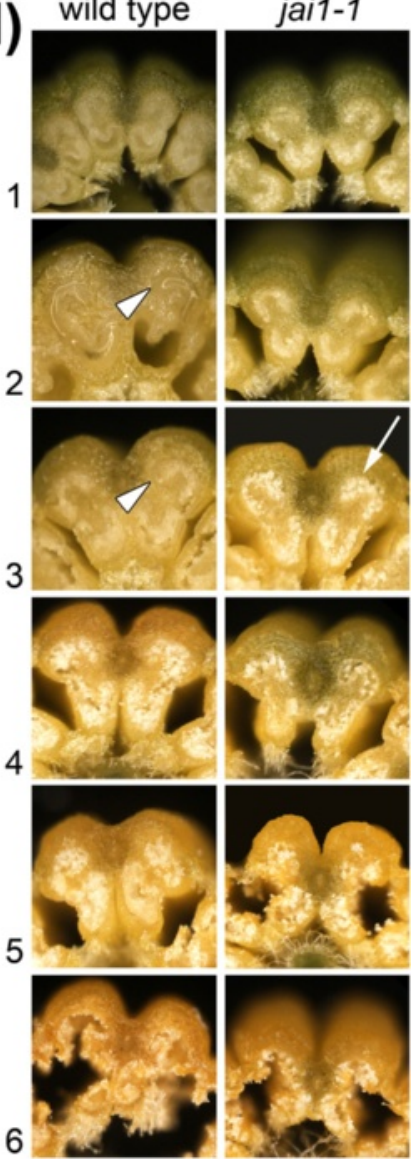

Figure 6 Premature dehiscence in stamens of jai1-1. (a) Osmolality in stamens of wild type and jai1-1 plants. (b) Occurrence of starch in anther tissues of wild type and jail-1 plants. Sections of fresh stamens were stained with iodine potassium iodide resulting in a black and brownish coloration of amylose and amylopectin, respectively. Note the strong staining in stamen of wild type plants showing a high number of starch grains and high levels of amylopectin, whereas stamen of jail-1 show only a few starch grains and almost no amylopectin. Bar represents $100 \mu \mathrm{m}$ for all micrographs. (c) Relative water content in stamens of wild type and jail-1. (d) Cross-sections of fresh stamens of the six developmental stages in wild type and jai 1-1. Note the appearance of fluids in the locule of wild type stamen at stage 2 and 3 (arrow heads) being absent in jai 1-1. In contrast, jai1-1 pollen appear whitish (arrows) at early developmental stages pointing to premature pollen desiccation and accumulation of desiccation-related substances. Mean values + SD of stamens of the developmental stages indicated are shown in (a) and (c). ${ }^{*} P \leq 0.05,{ }^{* * *} P \leq 0.001$ according to Student's t-test $(n \geq 8)$. SD, standard deviation.

constitutive ET response, such as epinastic (epi, [33]), both in the Micro-Tom background [34], was determined in comparison to WT and jai1-1 (Figure 9). Consistent with ET function in senescence and dehiscence, $N R$ anthers exhibited a delayed pollen release, whereas epi anthers showed a premature pollen release. Here, similar to jai1-1, released pollen were already detectable in epi stamen of stage 4 , whereas almost no pollen were released from stamen of WT and NR in this stage. This leads to the conclusion that jasmonate-insensitivity in jai1-1 mimics the constitutive ET response in the epi mutant.

As genetic proof, jai1-1 and NR were crossed and stamens of the double mutant were analyzed regarding pollen development and release. As visible in semi-thin cross sections of jai1-1 NR anthers, pollen development at early stages was similar to that of the jai1-1 single mutant (Figure S7 in Additional file 2). The development of microspores and pollen occurred faster than in WT and $N R$ stamens and the tapetum was degraded in stage 1. From these data we conclude that at early stages, which are not related to ET function, jai1-1 dominates NR and introduction of ET insensitivity did not change the jai1-1 phenotype. However, a contrasting picture appeared at late stages of stamen development. Here, ET insensitivity rescued the jai1-1 phenotype. Pollen release and closure of stomium of the double mutant at stage 4 is similar to $N R$ (Figure 9, Figure S6c, d in Additional file 2). The data obtained by these approaches support the assumption that jasmonates function as inhibitors of premature rise of ET during stamen development in WT tomato. 


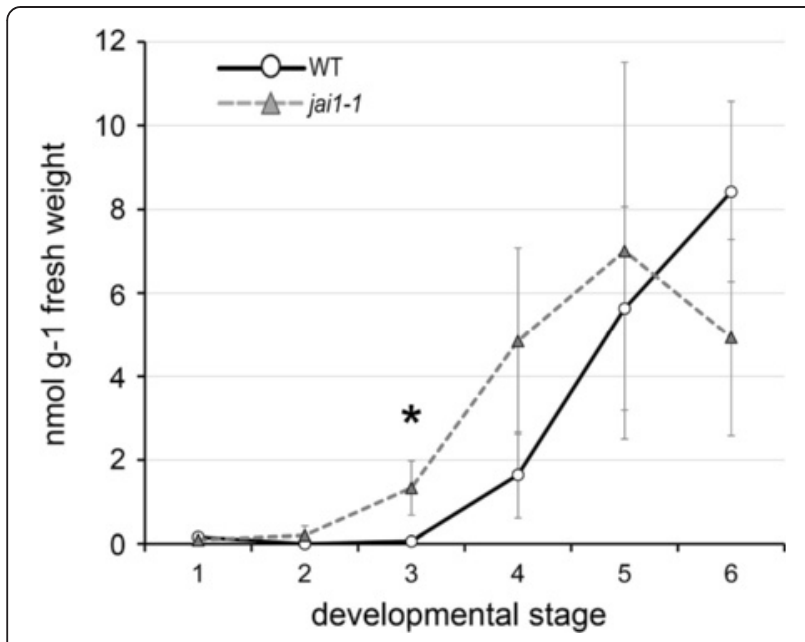

Figure 7 Levels of ACC in developing stamens of wild type and jail-1. Stamens of the respective stages were extracted and content of ACC was determined. Mean values \pm SD are shown. Data of the same developmental stage were compared between wild type and jai1-1 by Student's t-test ( $P \leq 0.05, \mathrm{n}=4$ ). ACC, 1-aminocyclopropane1-carboxylic acid; SD, standard deviation.

\section{Discussion}

Jasmonates, known as stress hormones, are also involved in the regulation of various developmental processes of plants. Jasmonates are crucial for plant fertility, since JA deficiency or insensitivity in A. thaliana results in male sterility characterized by delayed anther dehiscence, insufficient filament elongation and production of unviable pollen $[20,35]$. In contrast, JA insensitivity in tomato leads to a female sterile phenotype, although the development of stamen and pollen is also affected [23]. Therefore, jai1-1 stamens provide a useful tool for identifying JA and COI1-dependent processes that operate in male reproductive tissues of tomato. Comparing jai1-1 and WT stamens in terms of gene expression and metabolite accumulation, this study revealed that jasmonates regulate pollen nutrition and thereby pollen development, but most obviously they are an important regulator of the proper timing of stamen dehiscence via a temporal repression of ET biosynthesis and action.

In developing stamens of WT plants, JA and JA-Ile levels exhibited a maximum at an intermediate developmental stage (Figure 1), which was defined as buds of maximal size with opened sepals, but white petals. At this stage, stamens undergo a switch between the two developmental phases characterized as the histodifferentiation program (phase 1 of stamen development) and cell degeneration and dehiscence program (phase II of stamen development) [36]. Up to flower bud stage 3, developing pollen grains finished pollen mitosis, took up water and sugars from locular fluid and started to accumulate starch (Figure 3). The maximum jasmonate level coincided with the number of differentially accumulating transcripts in WT and jai1-1 stamens. In stages before reaching the JA maximum, that is, during phase I of stamen development, most of the differentially regulated genes exhibited higher transcript accumulation in WT than in jai1-1 stamens (Figure 2), indicating a positive regulatory role of jasmonates in phase I. Additionally, gene expression analysis revealed that positive regulation by JA appeared to be stronger in stages before reaching jasmonate maximum. Interestingly, this group contains genes, whose putative gene products might be responsible for pollen nutrition and water homeostasis in pollen and anther tissue. These alterations in expression pattern of jai1-1 stamens were accompanied by reduced metabolite levels, but also by a premature degradation of the tapetum, a high number of aborted pollen and the absence of locular fluid (Figures 3, 5 and 6).

Formation of viable pollen within the locules of the anther is dependent on nutritive contributions from the surrounding sporophytic tissue, and pollen development relies on the nutritive support of neighboring tapetal cells $[21,37]$. Developing microspores obtain their carbohydrate supply from the tapetum [38] and from degradation of callose surrounding the microspore tetrads [39]. During maturation, pollen grains receive their sugars directly from the locular fluid, since at the later stages of anther development the tapetum no longer exists [40]. The locular fluid contains large amounts of soluble compounds as a result of polysaccharide degradation [41]. However, premature death of tapetal cells results usually in the disruption of the nutrient supply to the microgametophytes, leading to their death $[42,43]$. Therefore, the premature degradation of the tapetum and the absence of the locular fluid in jai1-1 stamens may contribute to an inefficient pollen nutrition followed by abortion of microspores as well as by an accelerated and inefficient maturation of the remaining pollen. The diminished formation of vacuoles in pollen of jai1-1 plants (see Figure 3) might point to such an insufficient water and sugar uptake since both processes are assumed to be linked [41].

A different scenario was obtained upon transcript and metabolite profiling of stamens in phase II of development. In stages after the JA maximum, most of the differentially regulated genes appeared to be expressed at higher levels in jai1-1 than in WT stamen implicating a negative regulatory role of JA. Most prominently, transcripts of genes involved in ET biosynthesis (ACC synthase, ACC oxidase), ET signaling (transcription factors such as RIN, FRUITFULL, AP2/ERF, and receptors such as ETR6) and ET-response genes (AOX1B, Pirin-like, DEHYDRIN) exhibited higher levels in jai1-1. This was accompanied by a higher content in the ET precursor ACC, whose levels increased at least one stage earlier in jai1-1 than in WT stamens. Accordingly, some of the genes were down-regulated by application of JA to 

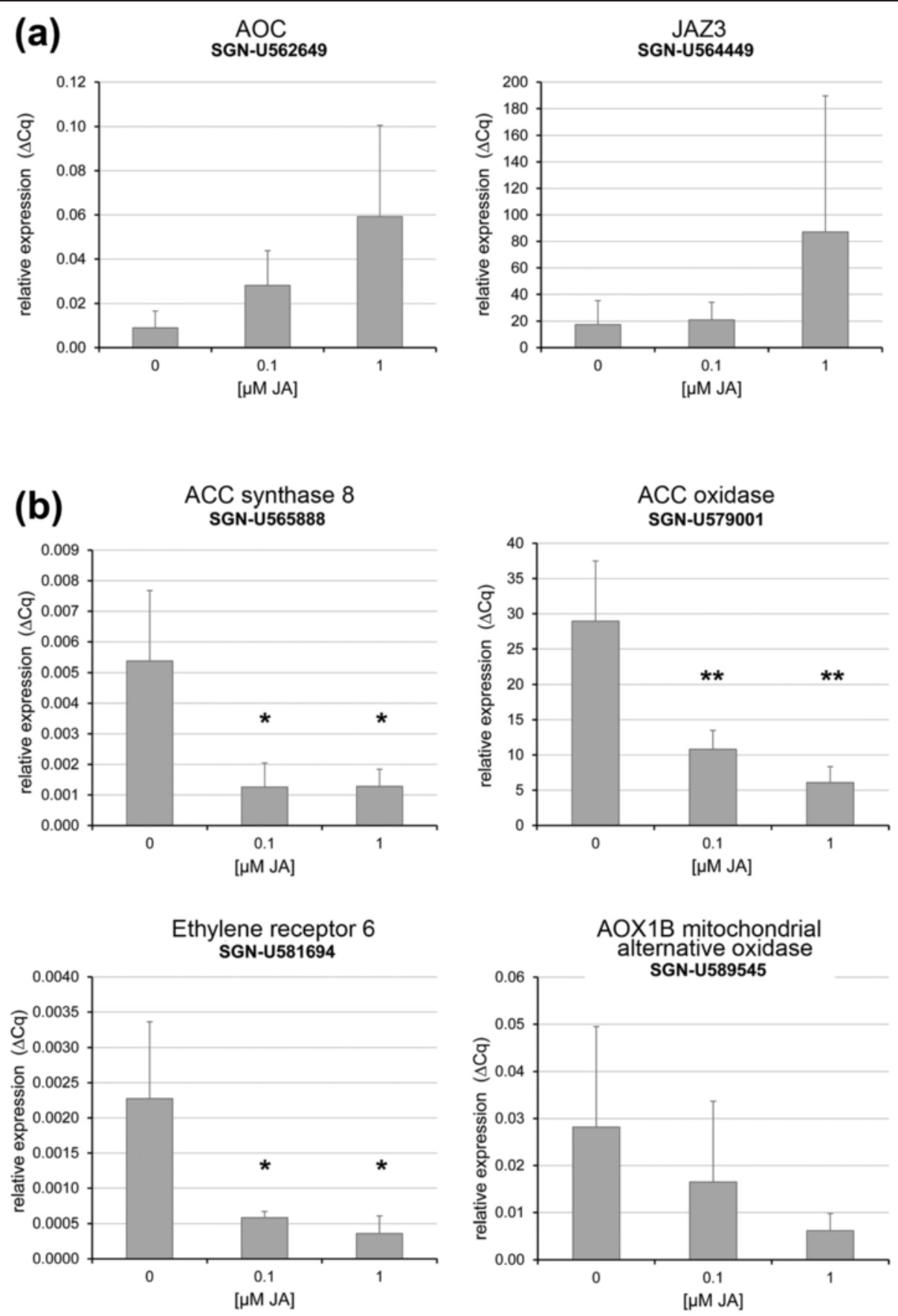

Figure 8 Transcript accumulation of selected JA-responsive and ET-related genes in stamens of JA-treated flowers buds. Flower buds in stage 2 were treated three times in an interval of 20 hours by spraying with JA solution in the concentration indicated. Stamens were harvested from flower buds at stage 5 (five hours after the last treatment). (a) Relative transcript levels of genes encoding early JA-induced genes in stamen of wild type plants. (b) Relative transcript levels of genes encoding ET biosynthetic enzymes, proteins involved in ET-signaling, and of ET-response genes in stamen of AOC-RNAi plants. All transcript levels were determined by RT-qPCR and set in relation to SITIP41. Mean values + SD are shown. Data of JA treated stamen were compared with stamen of control treatment $(0 \mu \mathrm{M} J \mathrm{~A})$ by Student's t-test $\left({ }^{*} P \leq 0.05,{ }^{* *} P \leq 0.01, \mathrm{n}=4\right)$. ET, ethylene; JA, jasmonic acid; SD, standard deviation.

flower buds of a SlAOC-RNAi line (Figure 9) supporting the hypothesis that jasmonates control biosynthesis and function of ET in a negative way.
Among the ET response genes were genes encoding polysaccharide degrading enzymes, such as endoglucanase 1 (Figure 4). This is in line with the fact that 

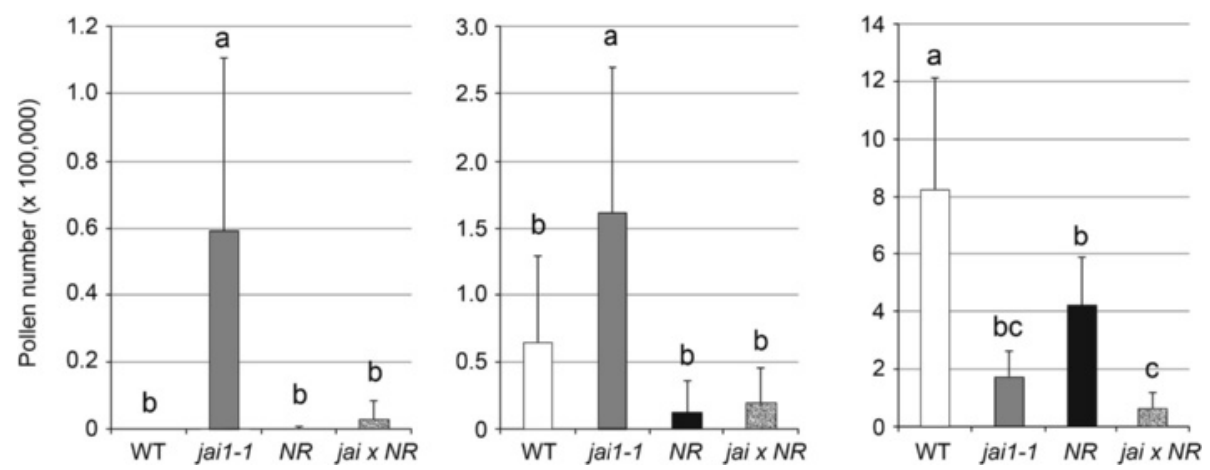

Figure 9 Pollen release from anthers of wild type, jai1-1 and mutants affected in ET-signaling. Dissected anthers of the developmental stage $4 \mathrm{~s}$ (a), 5 (b) and 6 (c) of wild type (WT), jai1-1, never ripe (NR), epinastic (epi) and the double mutant jai1-1 NR were shaken in PBS and released pollen were counted. The overproduction of ET in epi resulted in similar premature pollen release at stage 4 as detectable for jait-1, whereas pollen release in $N R$ and jail-1 NR is similar to WT. Note that the absolute numbers of released pollen are less in jail-1-based genotypes due to the high number of aborted pollen (see Figure 3). Mean values $+S D$ are shown $(n \geq 13$ ). Different letters designate statistically different values (ANOVA with Tukey's HSD test; $P \leq 0.01)$. ANOVA, analysis of variance; $E T$, ethylene; $\mathrm{HSD}$, honest significant difference; $\mathrm{SD}$, standard deviation.

hydrolytic enzymes and proteins linked to cell wall loosening are thought to be involved in anther dehiscence [27]. Along with that, osmotic active metabolites, such as proline, non-reducing sugars, such as sucrose, trehalose and 1-kestose, as well as protective proteins, such as dehydrin, were found to be accumulating in higher amounts in jai1-1 than in wild type stamen (Figures S4 and S5 in Additional file 2). The higher hexose levels in jai1-1 stamens might arise from an insufficient conversion of starch from sugars. Indeed, less starch was found in the anther tissues of jai1-1 stamens than in anthers of WT stamens, where a maximum of starch accumulation was detected in stage 3 and possibly resulted in a chemical formation of water (Figure 6). In turn, higher glucose and fructose contents in the jai1-1 might also function as osmoprotectants to compensate the loss of water released upon starch biosynthesis. Together, this could result in an increased dehydration within specific cell types and regions of the anther (Bonner and Dickinson, 1990). Certainly, the stomia of jai1-1 stamens exhibited a premature rupture (Figure $\mathrm{S} 7$ in Additional file 2) contributing to the early pollen release.

The enhanced expression of ET-related genes and the early accumulation of ACC in jai1-1 stamens suggest that a premature rise and action of ET occur in stamens of jai1-1 and leads to dehiscence and pollen release. This is consistent with the delayed and premature pollen release observed in stamen of the tomato mutants $N R$ and epi, respectively (Figure 9), thereby supporting the role of ET in dehiscence and pollen release (Scott et al., [26]). Most importantly, the genetic proof by creating the double mutant jai1-1 NR showed unequivocally that ET insensitivity led to a rescue of the phenotype of jai11 stamen at late developmental stages (Figure 9), but not at early stages (Figure S7 in Additional file 2). This supports the hypothesis that jasmonates have a positive regulatory role at phase I of stamen development, which is not related to ET, whereas jasmonates are necessary to prevent the early rise and action of ET in phase II regulating senescence and dehiscence.

ET and JA are found to be coordinately (cooperatively or antagonistically) regulated or exhibit opposite effects on many plant responses $[1,44,45]$. A synergistic crosstalk between JA and ET is known to occur preferentially for the response to necrotrophic pathogens [46], whereas they act antagonistically in regulation of the expression of wound-responsive genes $[47,48]$ and metabolite biosynthetic genes [49]. Furthermore, jasmonates repress apical hook formation [50], while ET has the opposite effect [51]. In Arabidopsis, JA and ET act in parallel to regulate timing of floral organ abscission [52]. Depending on developmental stages and physiological responses, JA affects ET signaling downstream of the ET receptors, since reduced JA levels might cause ET sensitivity in originally ET insensitive ein 2 mutants [53]. Recently, a model for the molecular mechanism for the antagonism between JA and ET signaling in the apical hook formation in A. thaliana was presented [44,54]: on the one hand, MYC2, a prominent member of the MYCtranscription factor-family activated by JA, can physically interact with the ET-activated transcription factor ETHYLENE INSENSITIVE3 (EIN3) to directly inhibit its transcriptional activity. On the other hand, MYC2 positively regulates expression of EIN3 BINDING FBOX PROTEIN1 (EBF1) by directly binding to its promoter leading to an increase in EBF1-promoted EIN3 degradation. However, applying strong statistical criteria neither $M Y C 2$ nor $E B F 1$ were found among the differentially regulated genes in our dataset from tomato stamen. 


\section{Conclusions}

The characteristic phenotypic feature of jai1-1 flowers is a premature dehiscence and senescence of stamens visible by browning of the cone tip [23] leading to the hypothesis that function of the senescence-promoting hormone ET might be deregulated in this mutant. Obtained by global transcript and metabolite profiling, the presented data reveal a new scenario for the function of jasmonates and ET in the stamen development of tomato (Figure 10). During early stamen development jasmonates seem to promote processes related to pollen nutrition and water supply. In the later developmental stages, JA insensitivity in the jai1-1 mutant leads to a premature expression of some of the well-known master regulators in ET signaling, thereby leading to premature biosynthesis and action of ET.

The premature dehiscence of jai1-1 stamen is in contrast to the known effects of JA deficiency or insensitivity in A. thaliana, where in the corresponding mutants dehiscence of anthers appears to be delayed. In developing flowers of Arabidopsis WT plants, the highest JA levels occurred in the mature flower [55], and JA is absolutely required in stamen of flower stage 12 to enable

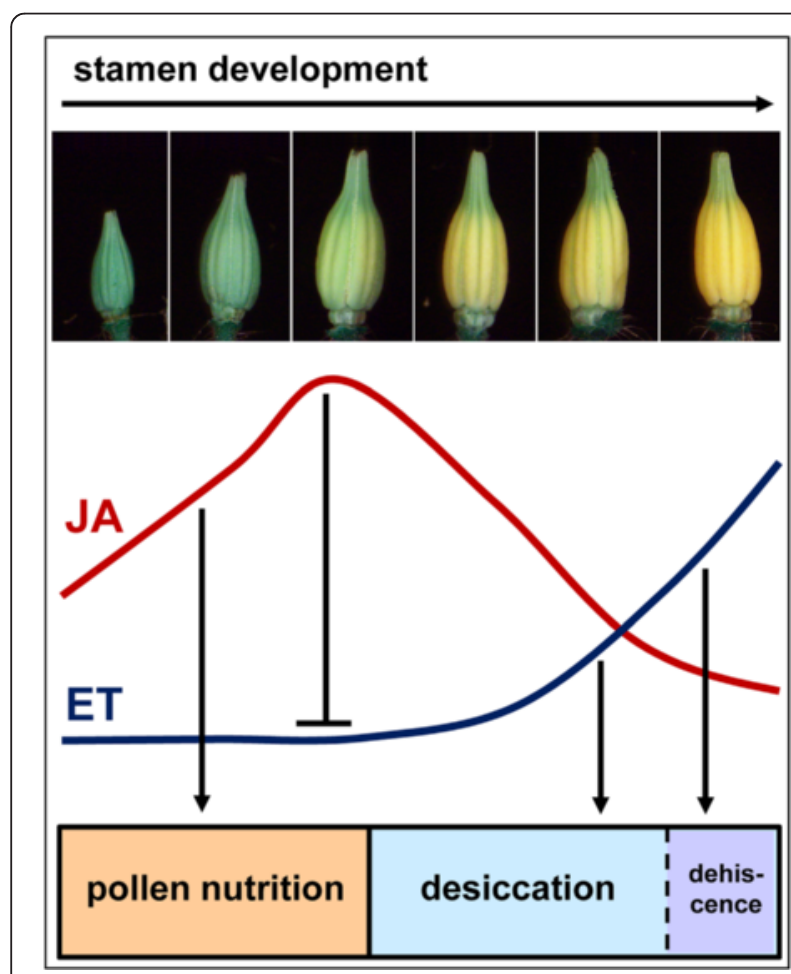

Figure 10 Schematic model of the role of jasmonates in stamen development of tomato. Jasmonate levels increase transiently during stamen development. In the first phase, increasing JA levels promote pollen nutrition and development. In the second phase of stamen development, jasmonates function as inhibitor of a premature rise of ethylene, which itself positively regulates anther dehiscence and pollen release filament elongation in the subsequent developmental stage [17]. This confirms a function of JA as a positive regulator in Arabidopsis to trigger the developmental switch that initiates the program for final stamen maturation and dehiscence. In tomato, however, the JA/JA-Ile content already started to decline at a stage before the desiccation process starts. Therefore, it is likely that jasmonates are not directly involved in the regulation of dehiscence of tomato anthers, but fulfill a regulatory role by controlling the dehiscence-promoting hormone ET to prevent a premature occurrence of this process. With this model, a new form of cross-talk between JA and ET in a plant developmental process becomes obvious. The elucidation of regulatory components that mediate this cross-talk will deliver new insights into the regulatory role of JA and ET in the development of tomato stamen.

\section{Methods}

Plant material, growth conditions, harvest of stamens, and JA treatment

Solanum lycopersicum plants cv. MicroTom wild type (WT), jai1-1 [23], NR and epi [34], and transgenic plants expressing 35S::AOC-RNAi [31] were grown in in a controlled growth chamber with 16 hours light $(300 \mu \mathrm{mol}$

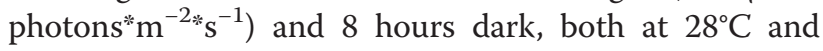
$50 \%$ humidity. Homozygous jai1-1 plants were selected by PCR according to [23]. Phenotypic markers, such as missing anthocyanin production in first leaves, protrusion of stigma and trichome-free fruits were additionally used for selection. AOC-RNAi expressing plants were selected by determination of $A O C$ transcript levels in leaves one hour after mechanical wounding (see below).

Crosses of jai1-1 and NR were performed by fertilization of NR ovaries with jai1-1 pollen. Seeds of the resulting F1 generation were germinated on $200 \mu \mathrm{M}$ ACC to select ET-insensitive plants, which do not show the typical triple response. Plants being homozygous for jai1-1 were subsequently selected by PCR according to [23].

Harvest of stamens was performed using five- to sixweek old plants showing the first open flowers. Stamens of defined developmental stages were harvested in a very strict time window of 30 minutes starting at four hours after the onset of the light period, collected on dry ice, transferred to liquid nitrogen and stored at $-80^{\circ} \mathrm{C}$. Stamens of all inflorescences were harvested for metabolite measurements, whereas those of primary inflorescences were used for transcript profiling. Harvesting time for stamens subjected to phytohormone quantification was expanded to 90 minutes and stamens of primary and secondary inflorescences were used.

Treatment of flower buds with JA was done by spraying $260 \mu \mathrm{l}$ of an aqueous JA solution $(0.1 \mu \mathrm{M}$ and $1 \mu \mathrm{M})$ three times during an interval of 20 hours starting with buds at stage 2. During this time, flowers buds developed to 
stage 5 and stamen were harvested five hours after the last treatment. Spraying with water served as the control treatment.

\section{RNA isolation and qRT-PCR}

RNA isolation from homogenized material was performed using the RNAmini plant Kit (Qiagen, Hilden, Germany [56]) according to the supplier's instructions including on-column digestion of DNA for 30 minutes. RNA quality was tested by capillary electrophoresis using the QIAxcel Advanced System (Qiagen). First strand cDNA synthesis of $1 \mu \mathrm{g}$ RNA was performed in a final volume of $20 \mu \mathrm{l}$ with M-MLV Reverse Transcriptase, RNase H Minus, Point Mutant (Promega, Fitchburg, WI, USA) according to the supplier's protocol using oligo(dT) 19 primer.

A total of $3 \mu \mathrm{l}$ of cDNA (diluted 1:20) were mixed with $2 \mu \mathrm{l} 5 \times$ EvaGreen QPCR Mix II (Bio\&Sell, Feucht, Germany [57]), 2 pmol forward primer and 2 pmol reverse primer and $\mathrm{dH}_{2} \mathrm{O}$ (at $10 \mu \mathrm{l}$ ). QPCR primers for candidate genes were designed with the software CloneManager (Sci-Ed Software, [58]) using the corresponding sequences of the tomato genome (sol genomic network, [59]) (for primer sequences see Additional file 2: Table S3). PCR was done using qRT-PCR-System CFX Connect (Bio-Rad, München, Germany [60]) with the following protocol: denaturation $\left(95^{\circ} \mathrm{C}\right.$ for 15 minutes), amplification $\left(40\right.$ cycles of $95^{\circ} \mathrm{C}$ for 15 seconds and $60^{\circ} \mathrm{C}$ for 30 seconds) and melting curve $\left(95^{\circ} \mathrm{C}\right.$ for 10 seconds, $60^{\circ} \mathrm{C}$ heating up to $95^{\circ} \mathrm{C}$ with a heating rate of $0.5^{\circ} \mathrm{C} \mathrm{s}^{-1}$ ). Data were analyzed with CFX Manager Software (Bio-Rad). Relative gene expressions were calculated by the comparative Cq method [61] using SlTIP41 [62] as the constitutively expressed gene. Each reaction was measured in triplicate.

\section{GeneChip data analysis}

RNA isolated independently from three stamen samples per developmental stage (1, 3 and 6), all from WT and jai1-1, was analyzed using Agilent-Tomato $44 \mathrm{~K}$-full genome chips. Synthesis and purification of cDNA; synthesis, labeling, purification, quality control and fragmentation of cRNA; as well as hybridization, washing, and scanning of the chips were done by the service partner (Atlas Biolabs, Berlin, Germany) [63] according to the supplier's protocols.

Data analysis was performed using ArrayStar [64]. All samples were quantile normalized. To identify genes that were differentially expressed, pairwise comparison between WT and jai1-1 at the three different developmental stages were done. $P$-values were corrected according to the Benjamini-Hochberg method using the statistical package of ArrayStar. Genes were considered as differentially expressed when adjusted $P$-values were $\leq 0.01$ and fold change $\geq 8$. Sets of genes showing differential expression were obtained for each developmental stage. Gene annotation was done using data from 'Sol Genomics Network' and mapping results obtained by MapMan [65] followed by manual check and correction using nucleotide blast [66]. Generation of groups was performed with Excel as described for metabolites. The original Agilent GeneChip data as well as normalized data from this study are publicly available at ArrayExpress database [67] under accession number E-MTAB-2752.

\section{Determination of OPDA, JA, JA-lle and ACC}

Quantitative analysis of OPDA, JA and JA-Ile was done using $500 \mathrm{mg}$ of homogenized plant material per sample as described [24]. To determine content of ACC, $500 \mathrm{mg}$ of frozen and grinded material was extracted with $10 \mathrm{ml}$ methanol supplied with $50 \mathrm{ng}\left[{ }^{2} \mathrm{H}_{4}\right]-\mathrm{ACC}$ as internal standard. The homogenate was filtered and placed on a column filled with $3 \mathrm{ml}$ DEAE-Sephadex A25 (GE Healthcare, München, Germany [68]) followed by washing with $3 \mathrm{ml}$ methanol. The flow through was evaporated,

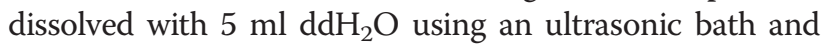
placed on a LiChrolutRP-18-column (Merck, Darmstadt,

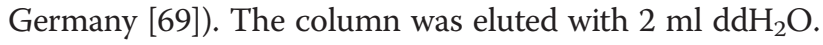
The evaporated eluate was dissolved in $200 \mu \mathrm{l}$ chloroform: $N, N$-diisopropylethylamine $(1: 1, \mathrm{v} / \mathrm{v})$ followed by derivatization with $10 \mu \mathrm{l}$ pentafluorobenzylbromide at $20^{\circ} \mathrm{C}$ overnight. After evaporation, samples were dissolved in $5 \mathrm{ml} \mathrm{n}$-hexane and passed through a Chromabond-SiOH column (Machery-Nagel, Düren, Germany [70]). The pentafluorobenzyl esters were eluted with $7 \mathrm{ml} \mathrm{n}$-hexane:diethylether $(2: 1, \mathrm{v} / \mathrm{v})$. Eluate was evaporated, dissolved in $100 \mu \mathrm{l}$ acetonitrile and analyzed by GC-MS as described by Miersch et al. [71]. All determinations were done using at least three independent biological replicates.

\section{Steady-state analysis of polar metabolites}

After homogenization in liquid nitrogen, $80 \pm 10 \mathrm{mg}$ material was extracted by shaking with $360 \mu \mathrm{l}$ methanol supplied with $6 \mu \mathrm{g}{ }^{13} \mathrm{C}_{6}$-sorbitol (Sigma-Aldrich, Munich, Germany) at $70^{\circ} \mathrm{C}$ for 15 minutes. After addition of $200 \mu$ chloroform, samples were shaken at $37^{\circ} \mathrm{C}$ for five minutes. Then $400 \mu \mathrm{l}$ $\mathrm{dH}_{2} \mathrm{O}$ was added and samples were mixed by vortexing. A polar metabolite fraction enriched for primary metabolites and small secondary compounds was obtained after centrifugation at $16,000 \times \mathrm{g}$ for five minutes at room temperature. For backup and validation purposes, 80- and 160- $\mu \mathrm{l}$ aliquots of the upper polar phase were dried by vacuum centrifugation (Concentrator 5301; Eppendorf, Hamburg, Germany [72]). Chemical derivatization $[73,74]$ and gas chromatography - electron impact ionization/time of flight - mass spectrometry (GC-EI/TOF-MS) metabolite profiling analysis $[75,76]$ was performed essentially as described previously. 
GC-EI/TOF-MS chromatograms were visually controlled, baseline corrected and exported in NetCDF file format using ChromaTOF software (Version 4.22; LECO, [77]). GC-MS data processing into a standardized numerical data matrix and compound identification were performed using the TagFinder software [78,79]. Compounds were identified by mass spectral and retention index matching to the reference collection of the Golm metabolome database (GMD, [80-82] and to the mass spectra of the NIST08 database [83]). Guidelines for manually performed metabolite identification were the presence of at least three specific mass fragments per compound and a retention index deviation $<1.0 \%$ [84].

All mass features of an experiment were normalized according to sample fresh weight, internal standard and maximum scaled. For quantification all mass features were evaluated for best specific, selective and quantitative representation of observed analytes. The WilcoxonMann-Whitney test for each developmental stage was performed to identify metabolites that occurred in different amounts between WT and jai1-1. Correction of $P$-values for multiple testing by the Benjamini-Hochberg method was done using Multi-experiment viewer software $\mathrm{MeV}$ (Version 4.6.2; [85-87]. Metabolites were considered as differentially present when adjusted $P$-values were $\leq 0.05$. Generation of groups was performed with Excel [88] using MAX normalized mean values of each metabolite and developmental stage. Grouping criteria were: developmental stage as depicted from the Venn diagram, direction of regulation and expression pattern in dependence on development. Down- and up-regulated metabolites were grouped according to their higher levels in WT and jai1-1, respectively.

\section{Determination of soluble sugar}

Determination of soluble sugar contents was performed photometrically by a coupled enzymatic assay as described previously [89].

\section{Determination of water content, osmolytic values and anther dehiscence}

Stamens were harvested and fresh weight (FW) was determined immediately. After drying at $50^{\circ} \mathrm{C}$ for one week, the dry weight (DW) was determined to calculate the water content (WC) according to the formula: $\mathrm{WC}=(\mathrm{FW}-\mathrm{DW}) / \mathrm{FW}$. To determine osmolytic values, stamens were harvested, frozen in liquid nitrogen and processed by several subsequently performed freezethaw steps followed by centrifugation at 17,000 $\times \mathrm{g}$ for 30 minutes using a nylon sieve $(41 \mu \mathrm{m})$ to collect the cell sap. At least $25 \mu \mathrm{l}$ of cell sap were used directly for measurement of osmolytic values with a cryoscopic osmometer (Roebling, Berlin, Germany, [90]).
For determination of anther dehiscence, flowers and buds were harvested and sepals and petals were removed. Stamens were transferred inversely into a tube containing $200 \mu \mathrm{l}$ phosphate-buffered saline and shaken for seven minutes. The number of released pollen was determined in technical triplicates using a counting chamber.

\section{Microscopy}

For light microscopic analysis stamens were fixed in 3\% (v/v) sodium cacodylate-buffered glutardialdehyde ( $\mathrm{pH} 7.2$ ), dehydrated in an ethanol series and embedded in epoxy resin [91]. Semi-thin sections $(1 \mu \mathrm{m})$ were stained with toluidine blue. Freshly harvested stamens were sectioned into $200 \mu \mathrm{m}$ thick cross sections using a vibrating blade microtome (VT 1000S; [92]). To evaluate starch accumulation, fresh sections were stained with one droplet of iodine potassium iodide solution for three to five minutes and washed with water.

Micrographs were taken using a Zeiss 'AxioImager' microscope (Zeiss, [93]) equipped with an AxioCam (Zeiss) and were processed through PHOTOSHOP 12.0.4 (Adobe Systems, [94]).

\section{Additional files}

Additional file 1: Table S1. Tomato genes found in the microarray
data to be differentially regulated in stamen of wild type and jai1-1 plants.
Table S2. Max-normalized data of significantly accumulating metabolites
obtained by steady-state analysis of soluble metabolites in stamen of wild
type and jai1-1 plants.
Additional file 2: Figure S1. Detailed grouping of max-normalized
differentially regulated genes according to their kinetics during development.
Figure S2. Transcript accumulation of selected JA-responsive genes in
stamens of wild type and jai1-1 plants. Figure S3. Detailed grouping of
max-normalized metabolites according to their kinetics during development.
Figure S4. Accumulation profiles of selected metabolites identified by
non-targeted metabolite profiling of stamens. Figure S5. Levels of soluble
sugars in developing stamen of wild type and jai1-1. Figure S6. Morphology
of stomia in stamen of stage 4 . Figure S7. Pollen development in NR and
jai1-1 NR. Table S3. Primer sequences.

\section{Abbreviations}

ACC: 1-aminocyclopropane-1-carboxylic acid; AOC: ALLENE OXIDE CYCLASE; COI1: CORONATINE INSENSITIVE 1; epi: epinastic; ET: ethylene; GC-MS: gas chromatography-mass spectroscopy; JA: jasmonic acid; JA-lle: JA isoleucine; jail-1: jasmonic acid-insensitive-1; JAZ: jasmonate ZIM domain protein; OPDA: cis-12-oxo-phytodienoic acid; NR: Never Ripe; RT-qPCR: reverse transcriptase quantitative polymerase chain reaction; TF: transcription factor; WT: wild type.

\section{Competing interests}

The authors declare that they have no competing interests.

\section{Authors' contributions}

SF and BH designed the research. SF, MW, RS, JD, GH and JK performed the research and analyzed the data. $\mathrm{BH}$ wrote the manuscript with the assistance of SF and JK. All authors read and approved the final manuscript.

\section{Acknowledgements}

We thank Birgit Ortel and Maria Pogoda (IPB Halle) for help in ACC quantification and experiments with AOC-RNAi plants, respectively, Gregg 
Howe (Michigan State University) for providing seeds of jai1-1 and Lázaro E. P. Peres (University of São Paulo, Brazil) for providing seeds of never ripe and epinastic, Alexander Erban (MPI Golm) for help in primary data analysis of metabolites and Benedikt Athmer (IPB Halle) for help in transcript data processing. Claus Wasternack, Carolin Delker and Alain Tissier (IPB Halle) are highly acknowledged for critical reading of the manuscript. The authors thank the Deutsche Forschungsgemeinschaft (DFG, HA2655/12-1,2) for financial support.

\section{Author details}

${ }^{1}$ Leibniz Institute of Plant Biochemistry, Weinberg 3, D06120 Halle, Germany. ${ }^{2}$ Martin Luther University Halle Wittenberg, Biocenter, Electron Microscopy, Weinbergweg 22, D06120 Halle, Germany. ${ }^{3}$ Max Planck Institute of Molecular Plant Physiology, Am Muehlenberg 1, D14476 Potsdam, (OT) Golm, Germany. ${ }^{4}$ Present address: Department of Botany I, University of Würzburg, Julius-von-Sachs-Platz 2, D97082 Würzburg, Germany.

Received: 11 March 2015 Accepted: 25 March 2015 Published online: 21 April 2015

\section{References}

1. Wasternack C, Hause B. Jasmonates: biosynthesis, perception, signal transduction and action in plant stress response, growth and development. An update to the 2007 review in Annals of Botany. Ann Bot. 2013;111:1021-58.

2. Vick BA, Zimmerman DC. The biosynthesis of jasmonic acid: a physiological role for plant lipoxygenase. Biochem Biophys Res Comm. 1983;111:470-7.

3. Feussner I, Wasternack C. The lipoxygenase pathway. Annu Rev Plant Biol. 2002:53:275-97.

4. Schaller F, Biesgen C, Müssig C, Altmann T, Weiler EW. 12-Oxophytodienoate reductase 3 (OPR3) is the isoenzyme involved in jasmonate biosynthesis. Planta. 2000;210:979-84.

5. Ziegler J, Stenzel I, Hause B, Maucher H, Hamberg M, Grimm R, et al. Molecular cloning of allene oxide cyclase: the enzyme establishing the stereochemistry of octadecanoids and jasmonates. J Biol Chem. 2000;275:19132-8.

6. Pauwels L, Morreel K, De Witte E, Lammertyn F, Van Montagu M, Boerjan W, et al. Mapping methyl jasmonate-mediated transcriptional reprogramming of metabolism and cell cycle progression in cultured Arabidopsis cells. Proc Natl Acad Sci U S A. 2008;105:1380-5.

7. Bruce TJ, Matthes MC, Chamberlain K, Woodcock CM, Mohib A, Webster B, et al. cis-Jasmone induces Arabidopsis genes that affect the chemical ecology of multitrophic interactions with aphids and their parasitoids. Proc Natl Acad Sci U S A. 2008;105:4553-8.

8. Wasternack C. Jasmonates: an update on biosynthesis, signal transduction and action in plant stress response, growth and development. Ann Bot. 2007:100:681-97.

9. Kramell R, Miersch O, Hause B, Ortel B, Parthier B, Wasternack C. Amino acid conjugates of jasmonic acid induce jasmonate-responsive gene expression in barley (Hordeum vulgare L.) leaves. FEBS Lett. 1997;414:197-202.

10. Chini A, Fonseca S, Fernandez G, Adie B, Chico JM, Lorenzo O, et al. The JAZ family of repressors is the missing link in jasmonate signalling. Nature. 2007:448:666-71

11. Fonseca S, Chini A, Hamberg M, Adie B, Porzel A, Kramell R, et al. (+)-7-isojasmonoyl-L-isoleucine is the endogenous bioactive jasmonate. Nat Chem Biol. 2009:5:344-50

12. Thines B, Katsir L, Melotto M, Niu Y, Mandaokar A, Liu G, et al. JAZ repressor proteins are targets of the SCF ${ }^{\mathrm{CO} I 1}$ complex during jasmonate signalling. Nature. 2007:448:661-5.

13. Sheard LB, Tan X, Mao H, Withers J, Ben-Nissan G, Hinds TR, et al. Jasmonate perception by inositol-phosphate-potentiated COI1-JAZ co-receptor. Nature. 2010:468:400-5.

14. Xie DX, Feys B, James S, Nieto-Rostro M, Turner J. COl1: An Arabidopsis gene required for jasmonate-regulated defense and fertility. Science. 1998;280:1091-4.

15. McConn M, Browse J. The critical requirement for linolenic acid is pollen development, not photosynthesis, in an Arabidopsis mutant. Plant Cell. 1996;8:403-16.

16. Ishiguro S, Kwai-Oda A, Ueda J, Nishida I, Okada K. The DEFECTIVE IN ANTHER DEHISCENCE1 gene encodes a novel phospholipase A1 catalyzing the initia step of jasmonic acid biosynthesis, which synchronizes pollen maturation. Plant Cell. 2001;13:2191-209.
17. Stintzi A, Browse J. The Arabidopsis male-sterile mutant, opr3, lacks the 12-oxophytodienoic acid reductase required for jasmonate synthesis. Proc Natl Acad Sci U S A. 2000;97:10625-30.

18. Sanders $P$, Lee $P$, Biesgen C, Boone J, Beals T, Weiler E, et al. The Arabidopsis DELAYED DEHISCENCE1 gene encodes an enzyme in the jasmonic acid synthesis pathway. Plant Cell. 2000:12:1041-61.

19. Browse J. Jasmonate passes muster: a receptor and targets for the defense hormone. Annu Rev Plant Biol. 2009;60:183-205.

20. Browse J. The power of mutants for investigating jasmonate biosynthesis and signaling. Phytochemistry. 2009:70:1539-46.

21. Ma H. Molecular genetic analyses of microsporogenesis and microgametogenesis in flowering plants. Annu Rev Plant Biol. 2005;56:393-434.

22. Li L, Li C, Howe G. Genetic analysis of wound singaling in tomato. Evidence for a dual role of jasmonic acid in defence and female fertility. Plant Physiol. 2001;127:1414-7.

23. Li L, McCaig B, Wingerd B, Wang J, Whaton M, Pichersky E, et al. The tomato homolog of CORONATINE-INSENSITIVE1 is required for the maternal control of seed maturation, jasmonate-signaled defense responses, and glandular trichome development. Plant Cell. 2004;16:126-43.

24. Hause B, Stenzel I, Miersch O, Maucher H, Kramell R, Ziegler J, et al. Tissue-specific oxylipin signature of tomato flowers - allene oxide cyclase is highly expressed in distinct flower organs and vascular bundles. Plant J. 2000;24:113-26.

25. Bonner $L$, Dickinson HG. Anther dehiscence in Lycopersicon esculentum. 2. Water relations. New Phytol. 1990;115:367-75.

26. Scott RJ, Spielman M, Dickinson HG. Stamen structure and function. Plant Cell. 2004;16:\$46-60

27. Wilson ZA, Song J, Taylor B, Yang C. The final split: the regulation of anther dehiscence. J Exp Bot. 2011;62:1633-49.

28. Rieu I, Wolters-Arts M, Derksen J, Mariani C, Weterings K. Ethylene regulates the timing of anther dehiscence in tobacco. Planta. 2003;217:131-7.

29. Liu M, Pirrello J, Kesari R, Mila I, Roustan JP, Li Z, et al. A dominant repressor version of the tomato SI-ERF.B3 gene confers ethylene hypersensitivity via feedback regulation of ethylene signaling and response components. Plant J. 2013;76:406-19.

30. Rontein D, Basset G, Hanson AD. Metabolic engineering of osmoprotectant accumulation in plants. Metab Eng. 2002;4:49-56.

31. Goetz S, Hellwege A, Stenzel I, Kutter C, Hauptmann V, Forner S, et al. Role of cis-12-oxo-phytodienoic acid in tomato embryo development. Plant Physiol. 2012;158:1715-27.

32. Lanahan MB, Yen HC, Giovannoni JJ, Klee HJ. The Never Ripe mutation blocks ethylene perception in tomato. Plant Cell. 1994;6:521-30.

33. Barry C, Fox E, Yen HC, Lee S, Ying TJ, Grierson D, et al. Analysis of the ethylene response in the epinastic mutant of tomato. Plant Physiol. 2001;127:58-66

34. Carvalho R, Campos M, Pino L, Crestana S, Zsogon A, Lima J, et al. Convergence of developmental mutants into a single tomato mode system: 'Micro-Tom' as an effective toolkit for plant development research. Plant Methods. 2011;7:18

35. Song S, Qi T, Huang H, Xie D. Regulation of stamen development by coordinated actions of jasmonate, auxin, and gibberellin in Arabidopsis. Mol Plant. 2013;6:1065-73.

36. Goldberg RB, Beals TP, Sanders PM. Anther development: basic principles and practical applications. Plant Cell. 1993;5:1217-29.

37. Zhang D, Yang L. Specification of tapetum and microsporocyte cells within the anther. Curr Opin Plant Biol. 2014;17:49-55.

38. David-Schwartz R, Weintraub L, Vidavski R, Zemach H, Murakhovsky L, Swartzberg D, et al. The SIFRK4 promoter is active only during late stages of pollen and anther development. Plant Sci. 2013;199-200:61-70.

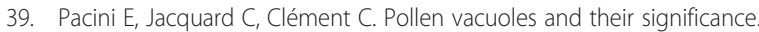
Planta. 2011;234:217-27.

40. Pressman E, Shaked R, Shen S, Altahan L, Firon N. Variations in carbohydrate content and sucrose-metabolizing enzymes in tomato (Solanum lycopersicum L.) stamen parts during pollen maturation. Amer J. Plant Sci. 2012;3:252-60.

41. Firon N, Nepi M, Pacini E. Water status and associated processes mark critical stages in pollen development and functioning. Ann Bot. 2012;109:1201-14

42. Ku S, Yoon $\mathrm{H}$, Suh $\mathrm{H}$, Chung YY. Male-sterility of thermosensitive genic male-sterile rice is associated with premature programmed cell death of the tapetum. Planta. 2003;217:559-65. 
43. Kawanabe T, Ariizumi T, Kawai-Yamada M, Uchimiya H, Toriyama K. Abolition of the tapetum suicide program ruins microsporogenesis. Plant Cell Physiol. 2006;47:784-7.

44. Song S, Huang H, Gao H, Wang J, Wu D, Liu X, et al. Interaction between MYC2 and ETHYLENE INSENSITIVE3 modulates antagonism between jasmonate and ethylene signaling in Arabidopsis. Plant Cell Online. 2014;26:263-79.

45. Zhu Z. Molecular basis for jasmonate and ethylene signal interactions in Arabidopsis. J Exp Bot. 2014;65:5743-8. doi:10.1093/jxb/eru349.

46. Pieterse CM, van der Does D, Zamioudis C, Leon-Reyes A, van Wees SC. Hormonal modulation of plant immunity. Annu Rev Cell Dev Biol. 2012;28:489-521.

47. Rojo E, León J, Sánchez-Serrano J. Cross-talk between wound signalling pathways determines local versus systemic gene expression in Arabidopsis thaliana. Plant J. 1999:20:135-42.

48. Lorenzo O, Chico JM, Sanchez-Serrano JJ, Solano R. JASMONATE-INSENSITIVE 1 encodes a MYC transcription factor essential to discriminate between different jasmonate-regulated defense responses in Arabidopsis. Plant Cell. 2004;16:1938-50

49. Mikkelsen MD, Petersen BL, Glawischnig E, Jensen AB, Andreasson E, Halkier BA. Modulation of CYP79 genes and glucosinolate profiles in Arabidopsis by defense signaling pathways. Plant Physiol. 2003;131:298-308.

50. Turner J, Ellis C, Devoto A. The jasmonate signal pathway. Plant Cell. 2002;14:S153-64

51. Guzmán P, Ecker JR. Exploiting the triple response of Arabidopsis to identify ethylene-related mutants. Plant Cell. 1990;2:513-23.

52. Kim J. Four shades of detachment: regulation of floral organ abscission. Plant Signal Behav. 2014;9, e976154.

53. Kim J, Patterson SE, Binder BM. Reducing jasmonic acid levels causes ein2 mutants to become ethylene responsive. FEBS Lett. 2013;587:226-30.

54. Zhang X, Zhu Z, An F, Hao D, Li P, Song J, et al. Jasmonate-activated MYC2 represses ETHYLENE INSENSITIVE3 activity to antagonize ethylene-promoted apical hook formation in Arabidopsis. Plant Cell. 2014;26:1105-17.

55. Nagpal P, Ellis CM, Weber H, Ploense SE, Barkawi LS, Guilfoyle TJ, et al. Auxin response factors ARF6 and ARF8 promote jasmonic acid production and flower maturation. Development. 2005;132:4107-18.

56. Qiagen. www.qiagen.com.

57. Bio\&Sell. http://www.bio-sell.de

58. Sci-Ed Software. http://www.scied.com.

59. SolGenomics Network. http://solgenomics.net.

60. BioRad. www.bio-rad.com.

61. Schmittgen TD, Livak KJ. Analyzing real-time PCR data by the comparative C(T) method. Nat Protoc. 2008;3:1101-8.

62. Expósito-Rodríguez M, Borges A, Borges-Pérez A, Pérez J. Selection of internal control genes for quantitative real-time RT-PCR studies during tomato development process. BMC Plant Biol. 2008;8:131.

63. Atlas Biolabs. http://www.atlas-biolabs.de/.

64. DNASTAR. www.dnastar.com.

65. MapMan. mapman.gabipd.org.

66. NCBI. www.ncbi.nlm.nih.gov.

67. ArrayExpress. http://www.ebi.ac.uk/arrayexpress/.

68. GE Healthcare. http://www.gelifesciences.com.

69. Merck. www.merck.de

70. Machery-Nagel. www.mn-net.com.

71. Miersch O, Neumerkel J, Dippe M, Stenzel I, Wasternack C. Hydroxylated jasmonates are commonly occurring metabolites of jasmonic acid and contribute to a partial switch-off in jasmonate signaling. New Phytol. 2008;177:114-27.

72. Eppendorf. http://www.eppendorf.com.

73. Fiehn O, Kopka J, Dormann P, Altmann T, Trethewey RN, Willmitzer L. Metabolite profiling for plant functional genomics. Nat Biotech. 2000;18:1157-61.

74. Roessner U, Wagner C, Kopka J, Trethewey RN, Willmitzer L. Simultaneous analysis of metabolites in potato tuber by gas chromatography-mass spectrometry. Plant J. 2000;23:131-42.

75. Wagner C, Sefkow M, Kopka J. Construction and application of a mass spectral and retention time index database generated from plant GC/EI-TOF-MS metabolite profiles. Phytochemistry. 2003;62:887-900.

76. Erban A, Schauer N, Fernie A, Kopka J. Nonsupervised construction and application of mass spectral and retention time index libraries from time-of-flight gas chromatography-mass spectrometry metabolite profiles.
In: Weckwerth W, editor. Metabolomics, vol. 358: Totowa, NJ: Humana Press; 2007: 19-38.

77. TagFinder. www.leco.com.

78. Luedemann A, Strassburg K, Erban A, Kopka J. TagFinder for the quantitative analysis of gas chromatography-mass spectrometry (GC-MS)-based metabolite profiling experiments. Bioinformatics. 2008;24:732-7.

79. Allwood JW, Erban A, de Koning S, Dunn WB, Luedemann A, Lommen A, et al. Inter-laboratory reproducibility of fast gas chromatography-electron impact-time of flight mass spectrometry (GC-El-TOF/MS) based plant metabolomics. Metabolomics. 2009;5:479-96.

80. Golm metabolome database. http://gmd.mpimp-golm.mpg.de/

81. Kopka J, Schauer N, Krueger S, Birkemeyer C, Usadel B, Bergmüller E, et al. GMD@CSB.DB: the Golm Metabolome Database. Bioinformatics. 2005;21:1635-8.

82. Hummel J, Strehmel N, Selbig J, Walther D, Kopka J. Decision tree supported substructure prediction of metabolites from GC-MS profiles. Metabolomics. 2010;6:322-33.

83. NIST08. http://wWw.nist.gov/srd/mslist.htm

84. Strehmel N, Hummel J, Erban A, Strassburg K, Kopka J. Retention index thresholds for compound matching in GC-MS metabolite profiling J Chromatography B. 2008;871:182-90.

85. MeV. http://tm4.org/mev.html.

86. Saeed Al, Sharov V, White J, Li J, Liang W, Bhagabati N, et al. TM4: a free, open-source system for microarray data management and analysis. Biotechniques. 2003;34:374-8.

87. Saeed Al, Bhagabati NK, Braisted JC, Liang W, Sharov V, Howe EA, et al. TM4 microarray software suite. In: Alan K, Brian O, editors. Methods in Enzymology, vol. 411: Amsterdam, The Netherlands: Academic Press; 2006. p. 134-93

88. Microsoft. www.office.microsoft.com/de-de/excel.

89. Schaarschmidt S, Qu N, Strack D, Sonnewald U, Hause B. Local induction of the alc gene switch in transgenic tobacco plants by acetaldehyde. Plant Cell Physiol. 2004:45:1566-77.

90. Roebling $\mathrm{GmbH}$. www.pro-4-pro.com.

91. Spurr A. A low-viscosity epoxy resin embedding medium for electron microscopy. J Ultrastructure Res. 1969;26:31-43.

92. Leica Microsystems. www.leica-microsystems.com.

93. Carl Zeiss GmbH. http://www.zeiss.com.

94. Adobe. http://www.adobe.com.

\section{Submit your next manuscript to BioMed Central and take full advantage of:}

- Convenient online submission

- Thorough peer review

- No space constraints or color figure charges

- Immediate publication on acceptance

- Inclusion in PubMed, CAS, Scopus and Google Scholar

- Research which is freely available for redistribution 